\title{
Procedure Directionality
}

National Cancer Institute

\section{Source}

National Cancer Institute. Procedure Directionality. NCI Thesaurus. Code C117527.

A qualifier for the direction on the body the procedure is performed. 